\title{
Reliability and validity of the Finnish version of the American Shoulder and Elbow Surgeons Standardized Shoulder Assessment Form, patient self-report section
}

\author{
Kirsi Piitulainen ${ }^{1,2^{*}}$, Juha Paloneva ${ }^{3}$, Jari Ylinen ${ }^{2}$, Hannu Kautiainen ${ }^{4,5}$ and Arja Häkkinen ${ }^{1,2}$
}

\begin{abstract}
Background: The American Shoulder and Elbow Surgeons Standardized Shoulder Assessment Form (ASES) is one of the most widely used shoulder outcome tools in clinical work and in scientific studies. However, it has not been validated in the Finnish language. The aims of this study were to cross-culturally adapt the ASES to the Finnish language and to study the psychometric properties of the self-report section of the ASES.

Methods: A total of 105 patients with shoulder symptoms answered the questionnaires of the ASES, a single disability question, the Simple Shoulder Test (SST), and the Short-Form 36 Health Survey (SF-36). The reliability of the ASES questionnaire was studied using a test-retest procedure at 2-week intervals. Psychometric assessment was performed by testing the construct validity, internal consistency, the criterion validity, and the convergent validity of the ASES.
\end{abstract}

Results: The reproducibility and internal consistency of the ASES were $0.83(95 \% \mathrm{Cl} 0.70$ to 0.90$)$ and 0.88 (95\% Cl 0.84 to 0.91). There were no significant differences between the diagnostic groups in the pain scores from the ASES, and the function score was significantly higher in the instability group compared to the other groups. The convergent validity of the ASES correlated with the SST, $r=0.73(p<0.001)$; the single disability question, $r=-0.74(p<0.001)$; and the Physical Component Score of the SF-36, $r=0.57(p<0.001)$.

Conclusions: The Finnish version of the ASES proved to be a reliable and valid tool for assessing shoulder disabilities in patients with different shoulder diagnoses, including rotator cuff disease, instability, and osteoarthritis.

Keywords: The American Shoulder and Elbow Surgeons Standardized Assessment Form (ASES), Shoulder pain, Reliability, Validity

\section{Background}

Shoulder pain is the third most common musculoskeletal problem after low back pain and neck pain [1]. Shoulder pain is responsible for a remarkable amount of sick leave in western countries [2]. One-third of the population over 30 years of age reported shoulder pain during the last month [3]. When treating these patients, it is crucial to obtain information from the patient's point of view to

\footnotetext{
* Correspondence: kirsi.piitulainen@jyu.fi

'Department of Health Sciences, University of Jyvaskyla, PL 35, 40014 Jyvaskyla, Finland

${ }^{2}$ Department of Physical Medicine and Rehabilitation, Central Finland Health Care District, Jyvaskyla, Finland

Full list of author information is available at the end of the article
}

assess the level of symptom severity and the level of disability.

There are two types of commonly used patient-based outcome tools. First, the generic measures (e.g., SF-36, EuroQol, and WHOQOL) evaluate general health, overall disability, and quality of life. However, they are not sensitive enough to react to clinically relevant changes in a specific disease [4]. Second, disease-specific measurement instruments connect the symptoms and disability to a specific disorder. One of the most frequently used questionnaires concerning the shoulder is the self-report section of the American Shoulder and Elbow Surgeons Standardized Shoulder Assessment Form (ASES) [5]. It has been validated in many languages and is considered 
to be a reliable, valid, and responsive outcome tool [5-12]. The psychometric properties of the ASES are reported to be acceptable for clinical use throughout every target language [6-8,11,12].

The ASES questionnaire has been used extensively in Finland. In addition it is easy and quick for a patient to complete. However, the ASES questionnaire has not been validated in the Finnish language. Compared to other questionnaires for the functional evaluation of the shoulder, e.g. the Disabilities of the Arm, Shoulder and Hand Questionnaire (DASH), which was developed to be used in patients with any disorder in any joint of the upper limbs, the ASES is more joint-specific instrument and therefore, more responsive and effective as a shoulder research tool [13]. The purpose of this study was to cross-culturally adapt the self-report section of the ASES questionnaire and to demonstrate the reliability and validity of the ASES among Finnish-speaking patients with shoulder pain.

\section{Methods}

\section{Translation and cross-cultural adaptation}

The translation and cross-cultural adaptation were performed based on the guidelines proposed by Beaton et al. [14]. The first stage was an independent translation (English to Finnish) of the self-report section of the ASES by two professionals (each with Finnish as their first language). In the second stage, synthesis of the two translations was performed. In the third stage, a person not working in the field of medicine, whose first language is English, and who masters the linguistic and cultural aspects of the Finnish language, back-translated (Finnish to English) the synthesised version blinded to the purpose of the instrument. In the fourth stage, the translation of the Finnish version of the ASES was accepted by an expert committee. The pre-final version of the ASES was tested in few subjects with shoulder problems to probe about the understanding of the questionnaire. As none of the comments required changes in this final stage of the adaptation, the equivalence of the Finnish questionnaire was ensured. Finally, the form was tested in a population of 128 patients with various shoulder disorders [15]. The Finnish version of the ASES is available on the Internet page of the Clinical Musculoskeletal Diseases Research Group of the Central Finland Health Care District (http://www.ksshp.fi/fi-FI/Ammattilaiselle/ TULEStutkimus/Clinical_Musculoskeletal_Diseases_ Resear(45030)) and in this article [see Additional file 1].

\section{Patients, setting, and data collection}

The psychometric characteristics of the Finnish version of the patient self-report section of the ASES questionnaire were examined in a sample of 105 consecutive patients who were clinically diagnosed with a shoulder disorder and referred for specialised care (the outpatient clinics in the Department of Physical Medicine and Rehabilitation or the Department of Orthopaedics and Traumatology in Central Finland Hospital, Jyväskylä, Finland). Our aim was to recruit a sample of at least 100 patients. The shoulder diagnoses were classified on the basis of information retrieved from the patient's medical records and, if needed, radiologic examinations (e.g., plain radiographs or magnetic resonance imaging) by an orthopaedic surgeon (JP). The inclusion criteria were age over 18 years, shoulder symptoms, and ability to communicate in the written Finnish language. The only exclusion criterion was previous surgery in the affected shoulder less than 1 year ago. The patients answered a questionnaire package that included the self-report section of the ASES, the Simple Shoulder Test (SST) [16], the Short-Form 36 Health Survey (SF-36) [17], and clinical and socio-demographic data. The self-report section of the ASES questionnaire was administered twice. The first questionnaires were mailed to the patients and the patients completed those 2 weeks before arriving at the outpatient clinic of Physical and Rehabilitation Medicine or orthopaedic surgery and again a second time when they came to the clinic. At the clinic the patients were contacted personally by a physiotherapist and asked to complete the ASES questionnaire for the second time.

\section{Measurements}

The self-report section of the ASES form is divided into two sections: pain and activities of daily living. The total ASES score is derived from a pain question using the Visual Analogue Scale (VAS) ranging from $0 \mathrm{~mm}$ (no pain) to $100 \mathrm{~mm}$ (worst pain), in addition to function during activities of daily living (1. Put on a coat, 2. Sleep on your painful shoulder, 3. Wash back, 4. Manage toileting, 5. Comb hair, 6. Reach a high shelf, 7. Lift $10 \mathrm{lb}$ above shoulder, 8. Throw a ball overhand, 9. Do usual work, and 10. Do usual sport). These activities of daily living were assessed for each shoulder separately, and the 10 items were graded on a 4-point ordinal (Likert) scale. Scores ranged from 0 (unable to do the activity) to 3 (no difficulty in performing the activity). The pain score and the cumulative activities of daily living (ADL) score were weighted equally (50 points each) and combined for a total score (possible 100 points). The ASES score is equal to 5 ([100 - ASES pain VAS]/10 + ASES Cumulative ADL score/3). A single disability question ("How severe was your shoulder disability during the last week?"), the shoulder-specific Simple Shoulder Test (SST) [16], and the generic Short-Form 36 Health Survey (SF-36) [17] were used to check the convergent validity. The aforementioned SST has not been validated in the Finnish language; unlike the SF-36 has been validated [18]. The patients completed the ten items of activities of daily living in relation to both shoulders to find out how many patients 
had disorders in both shoulders, though these results are not reported in the present study. A few patients had both shoulders affected, but in the analysis we chose the shoulder for which the patient had visited the outpatient clinic. The patients also answered an additional question about whether their shoulder symptoms had been stable, improved, or worsened during the past 2 weeks. According to these answers, the patients were divided into three groups.

The patients were divided into four categories according to the clinical diagnosis made in the outpatient clinics: rotator cuff disease, osteoarthritis of the glenohumeral or acromioclavicular joint, instability, and other.

\section{Statistics}

The results are expressed as means with standard deviation (SD) or with $95 \%$ confidence intervals (95\% CIs), as counts with percentages, or frequency distributions. The 95\% CIs were obtained by bias-corrected bootstrapping (5000 replications). The "floor value" was defined as the worst possible value of the item or as the minimum total value of the scale. The "ceiling value" was the best possible value of the item or the maximum total value of the scale. The reliability of the scales was evaluated by calculating the intra-class correlation coefficient (ICC) and coefficient of reproducibility with the bias corrected and accelerated bootstrapping (5000 replications) confidence intervals. The internal consistency was estimated by calculating Cronbach's alpha. Item analysis of the ASES scales was performed by analysing the item discriminating power (corrected item correlation) and the item difficulty (item mean) depicted by the explanatory data analysis. Factor structure among the ASES items was analysed using a factor analysis with varimax rotation. Effect size ("d") was calculated by using the method for paired samples: mean baseline scores minus mean follow-up scores, divided by the pooled standard deviation. Effect size of 0.20 was considered small, 0.50 medium and 0.80 large. 95 percent confidence intervals $(95 \% \mathrm{CI})$ were obtained by bias-corrected bootstrapping (5000 replications). The correlation coefficients between the ASES and other patient-reported outcomes were calculated by the Spearman method using Sidak-adjusted probabilities.

\section{Ethics}

The study was approved by the ethics board of the Central Finland Health Care District (November 23, 2005, Dnro 46/2005). Written informed consent was obtained from all participants.

\section{Results}

A total of 105 patients were enrolled in the study (mean age 52 years, range 18-88). The mean (SD) shoulder pain was $56(28) \mathrm{mm}$. The most common reason for shoulder pain was rotator cuff disease (41\%). The demographic and clinical data of the study group are shown in Table 1.

Table 2 shows the floor and ceiling values of the initial assessment. The floor value was reached by five patients in the pain score of the ASES but not in the function score or in the total ASES index. Three patients reached the ceiling value in the pain section and one patient in the function score but not in the total ASES index. The total ASES score ranged from 2 to 99 .

When the questionnaire was administered for the first time, the mean (SD) total ASES score was 48 (23) for the patients with shoulder symptoms that had been stable between the first and the second measurement. For these patients, the reproducibility intra-class correlation coefficient was $0.83(95 \% \mathrm{Cl}=0.70$ to 0.90$)$. For the patients with shoulder symptoms that had improved, the reproducibility ICC was 0.69 (0.27 to 0.87$)$. For the patients with worsened symptoms, the reproducibility ICC was 0.77 (0.59 to 0.87 ) (Table 2).

The internal consistency estimate of Cronbach's alpha was 0.88 ( $95 \% \mathrm{Cl} 0.84$ to 0.91 ). The item analysis of the ASES showed that item 6 (reaching a high shelf) had the highest corrected item correlation, whereas item 10 (doing usual sport) had the lowest corrected item correlation. In addition, item 3 (washing back) had the lowest item

\begin{tabular}{lc}
$\begin{array}{l}\text { Table } \mathbf{1} \text { Socio-demographic and clinical data of patients } \\
\text { with shoulder disorders }\end{array}$ \\
\hline Variables & Values (N = 105) \\
\hline Males, n (\%) & $60(57)$ \\
Age, years, mean (SD) & $52(18)$ \\
Body mass index, mean (SD) & $28(5)$ \\
Education, years, mean (SD) & $13(4)$ \\
Employed, n (\%) & $38(36)$ \\
Symptomatic shoulder, n (\%) & \\
Right & $65(62)$ \\
Left & $40(38)$ \\
Pain, VAS (0-100), mean (SD) & \\
Shoulder & $56(28)$ \\
Upper limb & $25(33)$ \\
Neck & $19(26)$ \\
Back & $16(26)$ \\
Duration of shoulder pain, months, mean (SD) & $56(79)$ \\
Shoulder trauma, n (\%) & $51(49)$ \\
Diagnosis, n (\%) & \\
Rotator cuff disease & $43(41)$ \\
Glenohumeral or acromioclavicular arthritis & $27(26)$ \\
Glenohumeral instability & $23(22)$ \\
Other & $12(11)$ \\
\hline
\end{tabular}

SD standard deviation, VAS visual analogue scale. 
Table 2 Reproducibility of the ASES index

\begin{tabular}{|c|c|c|c|c|c|c|c|}
\hline & \multicolumn{4}{|c|}{ Baseline } & \multirow{2}{*}{$\begin{array}{c}\begin{array}{c}\text { Change from first to } \\
\text { second measurement }\end{array} \\
\text { Mean }(95 \% \mathrm{Cl}) \text { [Effect Size] }\end{array}$} & \multicolumn{2}{|c|}{ Reproducibility } \\
\hline & Mean (SD) & Range & Floor* N (\%) & Ceiling** N (\%) & & ICC $(95 \% \mathrm{Cl})$ & CR $(95 \% \mathrm{Cl})$ \\
\hline $\begin{array}{l}\text { Pain score, all patients } \\
(\mathrm{N}=105)\end{array}$ & $21.9(14.1)$ & $0-50$ & $5(5)$ & $3(3)$ & 4.0 (1.8 to 6.1$)[0.26]$ & $0.66(0.52$ to 0.77$)$ & 23 (19 to 28 ) \\
\hline Improved ( $N=25)$ & $26.9(14.4)$ & $0-48$ & $2(8)$ & $0(0)$ & 5.8 (0.5 to 11.2$)$ [0.42] & 0.50 (0.04 to 0.77$)$ & 27 (19 to 38 ) \\
\hline Stable $(\mathrm{N}=55)$ & $22.3(14.7)$ & $0-50$ & $2(4)$ & $3(5)$ & 3.9 (0.9 to 7.0$)[0.27]$ & 0.68 (0.46 to 0.82 ) & 23 (17 to 29$)$ \\
\hline Worsened $(N=25)$ & $15.9(9.8)$ & $0-36$ & $1(4)$ & $0(0)$ & $2.2(-1.6$ to 6.0$)$ [0.19] & 0.67 (0.37 to 0.83 ) & 18 (14 to 23 ) \\
\hline $\begin{array}{l}\text { Function score, all } \\
\text { patients }(\mathrm{N}=105)\end{array}$ & $25.5(11.5)$ & $2-50$ & $0(0)$ & $1(1)$ & $0.2(-1.3$ to 1.6$)[0.01]$ & 0.81 (0.71 to 0.88 ) & 14 (11 to 18$)$ \\
\hline Improved $(\mathrm{N}=25)$ & $27.5(11.4)$ & $3-46$ & $0(0)$ & $0(0)$ & 2.6 (-0.1 to 5.3$)[0.23]$ & 0.81 (0.51 to 0.93 ) & 13 (8 to 20$)$ \\
\hline Stable $(N=55)$ & $26.0(11.3)$ & $3-50$ & $0(0)$ & $1(2)$ & $-1.5(-3.4$ to 0.4$)[0.13]$ & 0.83 (0.64 to 0.92 ) & 14 (10 to 19$)$ \\
\hline Worsened $(N=25)$ & $22.5(12.1)$ & $1-40$ & $0(0)$ & $0(0)$ & 1.5 (-1.9 to 4.9) [0.12] & 0.79 (0.57 to 0.90$)$ & 16 (11 to 22$)$ \\
\hline $\begin{array}{l}\text { Total ASES, all } \\
\text { patients }(N=105)\end{array}$ & $47.4(22.8)$ & $2-99$ & $0(0)$ & $0(0)$ & 4.1 (1.4 to 6.9$)[0.18]$ & 0.79 (0.69 to 0.86$)$ & 29 (25 to 35$)$ \\
\hline Improved ( $N=25)$ & $54.5(24.1)$ & $3-93$ & $0(0)$ & $0(0)$ & 8.5 (1.5 to 13.4 )[0.37] & 0.69 (0.27 to 0.87$)$ & 36 (24 to 52 ) \\
\hline Stable $(N=55)$ & $48.3(22.8)$ & 7-99 & $0(0)$ & $0(0)$ & $2.4(-1.2$ to 5.9$)[0.10]$ & 0.83 (0.70 to 0.90$)$ & 26 (21 to 31$)$ \\
\hline Worsened $(N=25)$ & $38.5(19.2)$ & $2-73$ & $0(0)$ & $0(0)$ & $3.7(-2.1$ to 9.4$)$ [0.17] & 0.77 (0.59 to 0.87$)$ & 28 (21 to 35$)$ \\
\hline
\end{tabular}

*Worst possible value (Pain and function: 0, Total ASES: 0) of the item or minimum total value of the scale.

**Best possible value (Pain and function: 50, Total ASES: 100) of the item or maximum total value of the scale.

ASES American Shoulder and Elbow Surgeons Standardized Shoulder Assessment Form, ICC intra-class correlation coefficient, CR coefficient of repeatability.

means, and item 4 (managing toileting) had the highest item means (Figure 1).

The factor analysis performed for construct validity showed that ASES was loaded on one factor that explained $66 \%$ of the total variance.

The total ASES index was the lowest in the glenohumeral or acromioclavicular arthritis group and the highest in the instability group. There was no statistical difference

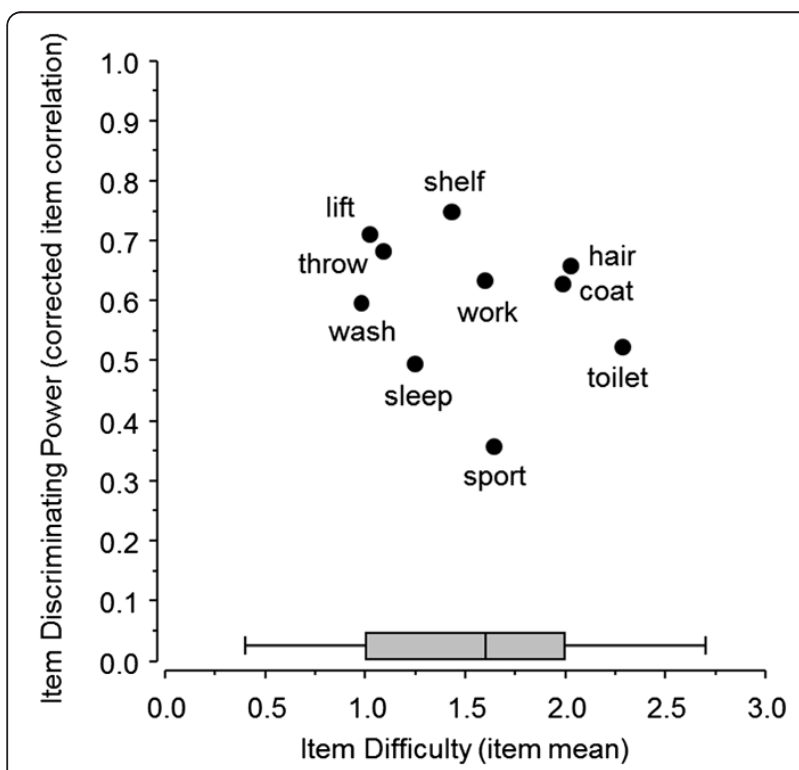

Figure 1 Item analysis for the function items of the ASES. The bar denotes the median and interquartile range. between the diagnostic groups in pain score, and the function score was significantly higher in the instability group compared to the other groups $(\mathrm{p}=0.035)$ (Figure 2).

The baseline data are presented in Table 3. The correlations between the total ASES index and the SST scale and the single disability question (How severe was your shoulder disability during the last week) were $0.73(\mathrm{p}<0.001)$ and $-0.74(\mathrm{p}<0.001)$. The mean shoulder disability scored by a single disability question was 54 (28). The correlations between the total ASES index and Physical Functioning, Role Physical, Role Emotional, Social Functioning and Bodily Pain from the SF-36 were statistically significant (Table 3 ). When the eight dimensions of the SF-36 were aggregated into summary scores, the correlations between the total ASES score and the Physical Component Summary and Mental Component Summary of the SF-36 were $0.57(\mathrm{p}<0.001)$ and $0.21(\mathrm{p}=\mathrm{ns})$.

During the translation process from English to Finnish and backward translation into English only minor linguistic and cultural differences between the translations emerged. The question of activities of daily living about lifting $10 \mathrm{lbs}$ above the shoulder was adapted to the metric system. The original ASES uses the U.S. Unit system. The translated weight is $4 \mathrm{~kg}$ in our study.

\section{Discussion}

In the present study, we assessed the cross-cultural adaptation and the psychometric properties of the selfreport section of the ASES questionnaire to the Finnish 


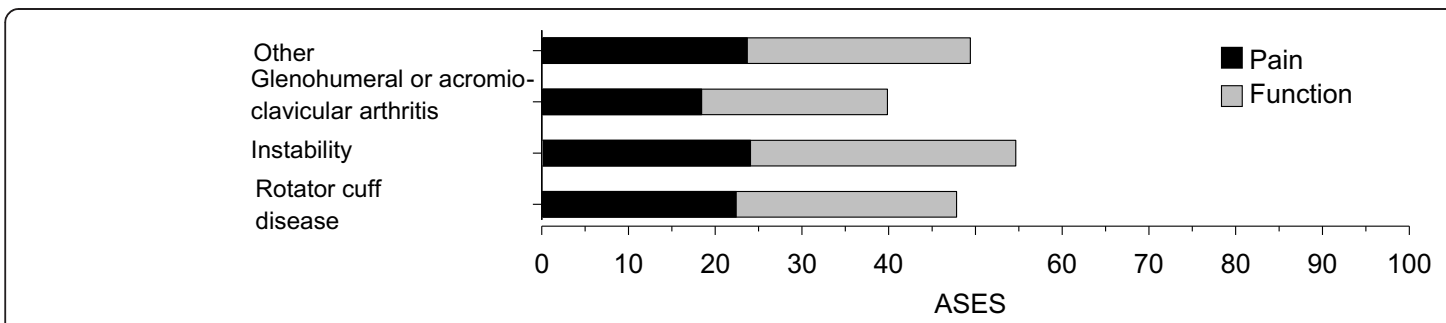

Figure 2 Pain and function scores of the ASES index in different diagnosis groups.

language. We demonstrated that this version of the ASES has good reliability and validity.

It has been suggested that a questionnaire reaching a floor or ceiling value of over $15 \%$ should be omitted [14]. The present study had even lower floor and ceiling effects than $15 \%$. One possible interpretation of this might be that a real floor or ceiling effect does not exist when using the Finnish ASES questionnaire. Kocher et al. [9] examined the floor and ceiling effect of the total ASES scale with different patient subsets (shoulder instability, rotator cuff disease, glenohumeral arthritis), and they found that only $1.3 \%$ of the patients with shoulder instability had a ceiling effect. Thus, the ASES score seems to have enough categories to discriminate the patients with different disability levels and changes.

In the present study, the baseline values in the stable, improved, and worsened groups were consistent. By dividing the patients into three groups it was possible to find out, if the ASES could detect differences between patients who have reported to be stable and those whose symptoms have been changed. The change was statistically significant only in the improved group (Table 2). The reproducibility ICC of the total ASES index in all patients was 0.79 (95\% Cl: 0.69 to 0.86$)$, but it varied between moderate and good in the three groups. The reproducibility ICC $(95 \% \mathrm{Cl})$ was $0.83(0.70$ to 0.90$)$ in the stable group (Table 2). According to Portney and Watkins [19], an ICC $>0.75$ indicates an acceptable test-retest reliability score. Although the time interval between the first and the second measurement varies from 1 day to 4 weeks, the reproducibility ICC is $\geq 0.84$ in the previous studies (Table 4). This indicates that test-retest reliability of the ASES is quite high and stable in all studied languages [6,7,9-12].

In the present study, the internal consistency of the ASES was good, which indicates that several items that propose to measure the same general construct produce similar scores. The $\alpha$-values measuring internal consistency varied considerably ranging from 0.61 to 0.96 in the previous studies $[6,7,9,10,12]$ demonstrating

Table 3 Disability and health-related quality of life and their correlations with the patient self-report section of the ASES

\begin{tabular}{|c|c|c|c|c|}
\hline & \multirow[t]{2}{*}{ Mean (SD) } & \multicolumn{3}{|c|}{ Correlations } \\
\hline & & The total ASES & Pain score & Function score \\
\hline SST (scale 0-12) & $5(4)$ & $0.73^{* * *}$ & $0.54^{* * *}$ & $0.81^{* * *}$ \\
\hline A single disability question (scale $0-100$ ) & $54(28)$ & $-0.74^{* * *}$ & $-0.67^{* * *}$ & $-0.68^{* * *}$ \\
\hline \multicolumn{5}{|c|}{ Dimensions of SF-36 (scale $0-100$ ) } \\
\hline Physical Functioning & $64(25)$ & $0.51^{* * *}$ & $0.38^{* *}$ & $0.57^{* * *}$ \\
\hline General Health & $58(22)$ & 0.27 & 0.22 & $0.32^{*}$ \\
\hline Vitality & $60(21)$ & 0.58 & 0.21 & $0.32^{*}$ \\
\hline Mental Health & $73(21)$ & 0.26 & 0.23 & 0.27 \\
\hline Role Physical & $36(39)$ & $0.49^{* * *}$ & $0.41^{* * *}$ & $0.47^{* * *}$ \\
\hline Role Emotional & $67(42)$ & $0.37^{* *}$ & 0.28 & $0.42^{* * *}$ \\
\hline Social Functioning & $75(26)$ & $0.44^{* * *}$ & $0.37^{* *}$ & $0.46^{* * *}$ \\
\hline Bodily Pain & $41(21)$ & $0.68^{* * *}$ & $0.630 * * *$ & $0.58^{* * *}$ \\
\hline \multicolumn{5}{|c|}{ Summary Score of SF-36 (scale 0-100) } \\
\hline PCS & $36(10)$ & $0.57^{* * *}$ & $0.48^{* * *}$ & $0.56^{* * *}$ \\
\hline MCS & $52(12)$ & 0.21 & 0.17 & 0.25 \\
\hline
\end{tabular}

${ }^{*} \mathrm{p}<0.05,{ }^{* *} \mathrm{p}<0.01$ and ${ }^{* * *} \mathrm{p}<0.001$. Sidak adjusted probability.

SD standard deviation, ASES American Shoulder and Elbow Surgeons Standardized Shoulder Assessment Form, SST Simple Shoulder Test, SF-36 Short Form 36 Health Survey, PCS Physical Component Score, MCS Mental Component Score. 
Table 4 Summary of translation, cultural adaptation and validation studies of the ASES

\begin{tabular}{|c|c|c|c|c|c|c|c|c|}
\hline & $\begin{array}{l}\text { Number of } \\
\text { subjects (age } \\
\text { range, years) }\end{array}$ & $\begin{array}{l}\text { Language/ } \\
\text { validation study }\end{array}$ & $\begin{array}{l}\text { Time interval between } \\
\text { the first and the second } \\
\text { measurement }\end{array}$ & $\begin{array}{l}\text { Reproducibility } \\
\text { ICC }(95 \% \mathrm{Cl})\end{array}$ & $\begin{array}{l}\text { Internal consistency } \\
\text { (Cronbach's alpha) }\end{array}$ & $\begin{array}{l}\text { Convergent validity } \\
\text { ASES and other } \\
\text { questionnaire }\end{array}$ & $\begin{array}{l}\text { Convergent validity } \\
\text { ASES and SF-36 PCS }\end{array}$ & $\begin{array}{l}\text { Convergent validity } \\
\text { ASES and SF-36 MCS }\end{array}$ \\
\hline \multirow{3}{*}{$\begin{array}{l}\text { Piitulainen } \mathrm{K} \text { et al. } \\
\text { present data }\end{array}$} & $n=105$ & \multirow[t]{3}{*}{ Finnish } & \multirow[t]{3}{*}{2 weeks } & \multirow{2}{*}{$\begin{array}{l}0.83(0.70 \text { to } 0.90) \\
n=55\end{array}$} & \multirow{3}{*}{0.88 (0.84 to 0.91 ) } & SST & & \\
\hline & $(18-88)$ & & & & & $r=0.73$ & $r=0.57$ & $r=0.21$ \\
\hline & & & & $\begin{array}{l}0.79 \text { (0.69 to } 0.86) \\
n=105\end{array}$ & & $p<0.001$ & $p<0.001$ & ns \\
\hline \multirow[t]{3}{*}{ Celik D et al. [6] } & $n=63$ & \multirow[t]{3}{*}{ Turkish } & \multirow[t]{3}{*}{ 3-7 days } & 0.94 & \multirow[t]{3}{*}{0.88} & SPADI & & \\
\hline & \multirow[t]{2}{*}{$(18-74)$} & & & & & $r=-0.82$ & $r=0.02$ & $r=0.53$ \\
\hline & & & & & & $p<0.001$ & $p=0.82$ & $p<0.000$ \\
\hline \multirow[t]{3}{*}{ Yahia A et al. [12] } & $\mathrm{n}=80$ & \multirow[t]{3}{*}{ Arabic } & \multirow[t]{3}{*}{$1-3$ days $n=30$} & 0.96 (0.92 to 0.98$)$ & \multirow[t]{3}{*}{0.76} & SPADI & \multirow[t]{3}{*}{-} & \multirow[t]{3}{*}{-} \\
\hline & \multirow[t]{2}{*}{$(20-80)$} & & & & & $r=-0.80$ & & \\
\hline & & & & & & $p<0.001$ & & \\
\hline \multirow{6}{*}{$\begin{array}{l}\text { Padua R } \\
\text { et al. } 2010\end{array}$} & $n=50$ & \multirow[t]{6}{*}{ Italian } & \multirow[t]{6}{*}{7 days $n=20$} & 0.91 & \multirow[t]{6}{*}{0.85} & DASH & & \\
\hline & \multirow[t]{5}{*}{$(33-78)$} & & & & & $r=-0.92$ & $r=0.48$ & $r=-0.20$ \\
\hline & & & & & & $p<0.02$ & $p<0.01$ & ns \\
\hline & & & & & & OSQ & & \\
\hline & & & & & & $r=0.78$ & & \\
\hline & & & & & & $p<0.02$ & & \\
\hline \multirow{4}{*}{$\begin{array}{l}\text { Goldhahn J } \\
\text { et al. [7] }\end{array}$} & $n=118$ & \multirow[t]{4}{*}{ German } & \multirow[t]{4}{*}{7 days } & \multirow[t]{4}{*}{$0.93(0.90$ to 0.95$)$} & \multirow[t]{4}{*}{0.96} & SPADI & & \\
\hline & \multirow[t]{3}{*}{ (33 to 89 ) } & & & & & $r=0.92$ & $r=0.64$ & Overall SF-36 \\
\hline & & & & & & DASH & & $r=0.66$ \\
\hline & & & & & & $r=0.84$ & & \\
\hline \multirow[t]{3}{*}{ Kocher et al. [9] } & $n=1066$ & \multirow{3}{*}{$\begin{array}{l}\text { Validation } \\
\text { study English }\end{array}$} & \multirow[t]{3}{*}{4 weeks } & \multirow{3}{*}{$\begin{array}{l}0.94(n=56) \text { age } \\
\text { range } 15-78 \text { years }\end{array}$} & 0.61 instability 0.64 rotator & - & SF-12 & SF-12 \\
\hline & $(13-95)$ & & & & & & $r=0.32-0.58$ & $r=-0.09-0.11$ \\
\hline & & & & & & & $p<0.001-0.002$ & $p=0.27-0.67$ \\
\hline Michener & $n=63$ & Validation & 24 to 72 hours, and & 0.84 (0.75 to 0.91$)$ & 0.86 & Penn Score & & \\
\hline et al. [10] & $(20-81)$ & study English & after 3 to 4 weeks & & & $r=0.78$ & $r=0.40$ & $r=0.15$ \\
\hline & & & & & & $p<0.01$ & $p=0.001$ & $p=0.25$ \\
\hline
\end{tabular}

ASES American Shoulder and Elbow Surgeons Standardized Shoulder Assessment Form, ICC intra-class correlation coefficient, CI Confidence interval, SST, Simple Shoulder Test, SPADI Shoulder Pain and Disability Index, DASH Disability of Arm, Shoulder and Hand questionnaire, OSQ Oxford Shoulder Questionnaire, Penn Score the University of Pennsylvania Shoulder Score, SF-36 Short Form 36 Health Survey, PCS Physical Component Summary, MCS Mental Component Summary, SF-12 Short Form 12 Health Survey. 
that the homogeneity of the ASES items in a scale varies in all the studies (Table 4). The main reason for this may be the differences in the study samples. The recommended Cronbach's alpha for group comparisons is higher than 0.80 [20]. However, "very good" internal consistency may indicate that the items are too homogenous. From that point of view, our study expresses good reliability and demonstrates that the items of the Finnish ASES are reasonably related and still contribute unique information about the patient's status. In the present study, the factor analysis showed unidimensionality of the ASES. However, it has been suggested that factor analysis for the ASES was loaded in 2 dimensions [12]. The reason for this may be due to study group differences.

Our a priori hypotheses were accomplished, as the ASES questionnaire had a strong correlation with the SST, the Physical Component Score of the SF-36, and also with the single disability question (expressed on a visual analogue scale). This confirmed the construct validity and reassured us that these measurement procedures were measuring the same construct. In the previous studies, correlations between the ASES and other shoulderspecific or upper limb-specific questionnaires have been strong $[6,7,10,12]$. Correlation between the SST and the ASES has been found to be strong, which is consistent with the similarity in their constructs [21]. In the present study the SST score was more related to function score than pain score of the ASES (Table 3). The reason for this may be the fact that a half of the ASES consists of single value of pain VAS and another half consists of function score that is quite similar to the SST. There was not a statistically significant correlation between the ASES questionnaire and the Mental Component Score of the SF-36 (Table 3). This result demonstrates that the ASES disability questionnaire and the Mental Component Score of the SF-36 questionnaire do not measure the same entity. On the contrary, Çelik et al. [6] reported significant correlation between the ASES and the Mental Component Score of the SF-36, meanwhile correlation between the ASES and the Physical Component Score of the SF-36 was weak (Table 4). The differences in correlations may be due to differences in, e.g. sample size, age, reason for shoulder disorder.

The questionnaire showed to be highly acceptable, easily understood, and capable of being self-administered. Any suggestions for improving the wording were not given, except the question about lifting $10 \mathrm{lbs}$ above the shoulder was adapted to the metric system. Thus, the weight is $4 \mathrm{~kg}$ in our study. A variance of 4 to $5 \mathrm{~kg}$ has been used in most of the studies concerning the validation of the ASES questionnaire [6-9,11].

The strength of the present study is that the subjects represented a very large range of ages and many different shoulder diagnoses. Another strength of this study is that the patients were grouped into stable, improved, and worsened categories. Using this subgroup analysis, we could assess the patients whose symptoms had changed. Furthermore, earlier literature has recommended that functional status questionnaires be measured within a 2-week time interval to test their reproducibility [14]. In our study, the patients completed the ASES questionnaire twice: 2 weeks before and at the time of their arrival to the outpatient clinics of physical medicine and rehabilitation or orthopaedics and traumatology. This procedure was applied to minimise the possibility that the patients received new treatments, which would potentially influence the responses of the second assessment, between these two time points.

A limitation of our study is that it was performed in a hospital setting. The patients were collected from the outpatient clinics of a single hospital following referral to specialised care. The patients had chronic shoulder problems, and they were examined by specialists. Thus, the sample assessed in this study may not represent subjects with shoulder pain in the entire population.

\section{Conclusions}

The self-report section of the Finnish ASES is a reliable and valid tool and can therefore be used as an instrument to assess shoulder disability among Finnish patients of different ages with different shoulder diagnoses.

\section{Additional file}

Additional file 1: ASES suomi that presents the Finnish American Shoulder and Elbow Surgeons Standardized Shoulder Assessment Form.

\section{Abbreviations}

ASES: American Shoulder and Elbow Surgeons Standardized Shoulder Assessment Form; SST: Simple Shoulder Test; SF-36: Short-Form 36 Health Survey; EuroQol: European Quality of life scale; WHOQOL: World Health Organization Quality of Life; HRQOL: Health-Related Quality of Life.

\section{Competing interests}

The authors declare that they have no competing interests.

\section{Authors' contributions}

KP: correspondent author, participated in the design of the study, participated in the patient collection, drafted the manuscript and finished the manuscript. $J P, J Y$ and $\mathrm{AH}$ participated in the design of the study and revised the manuscript critically. HK, KP and AH performed the statistical analysis. HK also drafted the manuscript and revised the manuscript critically. All authors read and approved the final manuscript.

\section{Acknowledgements}

This study was supported by the Medical Research Foundation of Jyvaskyla Central Hospital, Finland. The authors would like to thank the personnel of the Department of Physical and Rehabilitation Medicine and Department of Orthopaedics and Traumatology in Central Finland Hospital for participating in the patient collection.

\section{Author details}

${ }^{1}$ Department of Health Sciences, University of Jyvaskyla, PL 35, 40014 Jyvaskyla, Finland. 'Department of Physical Medicine and Rehabilitation, 
Central Finland Health Care District, Jyvaskyla, Finland. ${ }^{3}$ Department of Surgery, Central Finland Health Care District, Jyvaskyla, Finland. ${ }^{4}$ Unit of Primary Health Care, Helsinki University Central Hospital, Helsinki, Finland. ${ }^{5}$ Department of General Practice, University of Helsinki, Helsinki, Finland.

${ }^{6}$ Unit of Primary Health Care, Kuopio University Hospital, Kuopio, Finland.

Received: 13 March 2014 Accepted: 4 August 2014

Published: 11 August 2014

\section{References}

1. Boykin RE, Heuer HJ, Vaishnav S, Millett PJ: Rotator cuff disease - basics of diagnosis and treatment. Rheumatol Rep 2010, 2:e1.

2. Viikari-Juntura E: Increasing evidence of physical loads as risk factors for specific shoulder disorders. Scand J Work Environ Health 2010, 36:185-187.

3. Aromaa A, Koskinen S: Work, Ability to Work and Health of the Finns in the Beginning of the 2000's. Helsinki: THL National Institute for Health and Welfare; $11 / 2010$

4. Linde L, Sorensen J, Ostergaard M, Horslev-Petersen K, Hetland ML Health-related quality of life: validity, reliability, and responsiveness of SF-36, 15D, EQ-5D [corrected] RAQoL, and HAQ in patients with rheumatoid arthritis. J Rheumato/ 2008, 35:1528-1537.

5. Richards RR, An K, Bigliani LU, Friedman RJ, Gartsman GM, Gristina AG, lannotti JP, Mow VC, Sidles JA, Zuckerman JD: A standardized method for the assessment of shoulder function. J Shoulder Elbow Surg 1994, 3:347-352.

6. Celik D, Atalar AC, Demirhan M, Dirican A: Translation, cultural adaptation, validity and reliability of the Turkish ASES questionnaire. Knee Surg Sports Traumatol Arthrosc 2013, 21:2184-2189.

7. Goldhahn J, Angst F, Drerup S, Pap G, Simmen BR, Mannion AF: Lessons learned during the cross-cultural adaptation of the American Shoulder and Elbow Surgeons shoulder form into German. J Shoulder Elbow Surg 2008, 17:248-254.

8. Knaut LA, Moser AD, Melo Sde A, Richards RR: Translation and cultural adaptation to the portuguese language of the American Shoulder and Elbow Surgeons Standardized Shoulder assessment form (ASES) for evaluation of shoulder function. Rev Bras Reumatol 2010, 50:176-189.

9. Kocher MS, Horan MP, Briggs KK, Richardson TR, O'Holleran J, Hawkins RJ: Reliability, validity, and responsiveness of the American Shoulder and Elbow Surgeons subjective shoulder scale in patients with shoulder instability, rotator cuff disease, and glenohumeral arthritis. J Bone Joint Surg Am 2005, 87:2006-2011.

10. Michener LA, McClure PW, Sennett BJ: American Shoulder and Elbow Surgeons Standardized Shoulder Assessment Form, patient self-report section: reliability, validity, and responsiveness. J Shoulder Elbow Surg 2002, 11:587-594.

11. Padua R, Padua L, Ceccarelli E, Bondi R, Alviti F, Castagna A: Italian version of ASES questionnaire for shoulder assessment: cross-cultural adaptation and validation. Musculoskelet Surg 2010, 94(Suppl 1):S85-90.

12. Yahia A, Guermazi M, Khmekhem M, Ghroubi S, Ayedi K, Elleuch MH: Translation into Arabic and validation of the ASES index in assessment of shoulder disabilities. Ann Phys Rehabil Med 2011, 54:59-72.

13. Kirkley A, Griffin S, Dainty K: Scoring systems for the functional assessment of the shoulder. Arthroscopy 2003, 19:1109-1120.

14. Beaton DE, Bombardier C, Guillemin F, Ferraz MB: Guidelines for the process of cross-cultural adaptation of self-report measures. Spine (Phila Pa 1976) 2000, 25:3186-3191.

15. Paloneva J, Koskela S, Kautiainen $\mathrm{H}$, Vanhala M, Kiviranta I: Consumption of medical resources and outcome of shoulder disorders in primary health care consulters. BMC Musculoskelet Disord 2013, 14:348.

16. Lippitt S, Harryman D, Matsen FA: A practical tool for evaluation of function: the Simple Shoulder Test. In The Shoulder: a Balance of Mobility and Stability. Edited by Matsen F, Fu F, Hawkins RJ. Rosemont (IL): American Academy of Orthopedic Surgeons; 1993:545-549.

17. Ware JE, Kosinski M, Keller SD: Sf-36 Physical and Mental Health Summary Scales: a User's Manual. Boston MA: The Health Institute; 1994.

18. Aalto A, Aro AR, Teperi J: RAND-36 as a Measure of Health-Related Quality of Life. Reliability, Construct Validity and Reference Values in the Finnish General Population. STAKES Sosiaali- ja terveysalan tutkimus- ja kehittämiskeskus. Research Reports 101. Helsinki: 1999.
19. Portney L, Watkins M: Foundations of clinical research: applications to practise. 2000

20. Streiner D, Norman G: Health Measurement Scales. A practical Guide to Their Development and Use. 2003.

21. Roy JS, MacDermid JC, Woodhouse LJ: Measuring shoulder function: a systematic review of four questionnaires. Arthritis Rheum 2009, 61:623-632.

doi:10.1186/1471-2474-15-272

Cite this article as: Piitulainen et al:: Reliability and validity of the Finnish version of the American Shoulder and Elbow Surgeons Standardized Shoulder Assessment Form, patient self-report section. BMC Musculoskeletal Disorders 2014 15:272.

\section{Submit your next manuscript to BioMed Central and take full advantage of:}

- Convenient online submission

- Thorough peer review

- No space constraints or color figure charges

- Immediate publication on acceptance

- Inclusion in PubMed, CAS, Scopus and Google Scholar

- Research which is freely available for redistribution

Submit your manuscript at www.biomedcentral.com/submit
C Biomed Central 